\title{
Valoración De La Composición Química De Fermentación Y Degradabilidad Ruminal In Vitro De Dietas Con Diferentes Inclusiones De Harina De Banano Y Urea
}

\author{
Víctor Godoy Espinoza \\ Juan Avellaneda Cevallos \\ Ecuador en la Universidad Técnica Estatal de Quevedo
}

doi: 10.19044/esj.2016.v12n3p123 URL:http://dx.doi.org/10.19044/esj.2016.v12n3p123

\begin{abstract}
The purpose of this study was to evaluate the chemical of in vitro ruminal fermentation of diets with different inclusions of banana flour and urea. The assessment and in vitro fermentation were performed in the laboratory of nutrition and metabolism Rumiologia Faculty of Animal Science. In the first phase the chemical composition is performed in the second stage fermentation in vitro degradability It was a desing completely random was applied, with four diets and four replications; repetition consisted of a bottle or container or in vitro digestibility.

Each bottle will be an experimental unit represent a repetition. Data were analyzed using the statistical package procedure Eva DE-A-Dva and mean differences were compared using the Tukey test $(\mathrm{p}<0.05)$.

The degradability of dry matter (DM) of the diet obtained in this study confirm the disappearance of nutrients as time passes $(2,6,14,24,36,48,72$ hours) reaching values above $70 \%$ digestibility which guarantees the quality of the diet. The $\mathrm{pH}$ in the rumen fermentation in vitro obtained in this research on diet with inclusions of banana flour and urea from 0 to 6 and 6 to 72 hours is not dropped to dangerous levels of critical thresholds for celulolisis.
\end{abstract}

Keywords: Banana flour, degradability of DM, fermentation

\section{Resumen}

El objetivo de ésta investigación fue evaluar la valoración química de fermentación ruminal in vitro de dietas con diferentes inclusiones de harina de banano y urea. La valoración de fermentación in vitro se realizaron en el laboratorio de Rumiologia y metabolismo nutricional de la Facultad de 
Ciencias Pecuarias. En la primera fase se realizó la composición química, en la segunda fase la degradabilidad in vitro de fermentación. Se aplicó un diseño completamente al azar, con cuatro dietas y cuatro repeticiones; la repetición estuvo constituida por un recipiente para digestibilidad in vitro. Cada frasquito es una unidad experimental. Los datos se analizaron utilizando el procedimiento del paquete estadístico DE Eva-A-Dva y las diferencias de medias fueron comparadas usando la Prueba de Tukey $(\mathrm{p}<0,05)$. La degradabilidad de la materia seca (MS) de la dieta obtenida confirman la desaparición de nutrientes a medida que pasa el tiempo (2, 6, 14, 24, 36, 48, 72 horas) alcanzando valores superiores al $70 \%$ de digestibilidad garantizando la calidad de la dieta. El pH en la fermentación ruminal in vitro obtenido en el transcurso de las distintas horas de incubación en dietas con inclusiones de harina de banano y urea de 0 a 6 y de 6 a 72 horas no descendió a niveles inferiores a 5.5 umbrales críticos peligrosos para la celulolisis o degradación de la fibra/celulosa esta ausencia de cambios de $\mathrm{pH}$, podría deberse a la presencia de un buffer o solución tampón en el medio de cultivo.

Palabras claves: Harina de banano, degradabilidad de la MS, fermentación

\section{Introducción}

Ecuador es un importante productor de banano, a tal punto que los estudios del mercado internacional (2012 el sector bananero ecuatoriano exportó USD 2,078,239.38 millones de dólares por concepto de divisas y 5,196,065.09 de toneladas ubicando al banano como el primer producto de exportación del sector privado del país y uno de los principales contribuyentes al fisco. Entre los productos no tradicionales, las exportaciones ecuatorianas de banano, representan el $45.34 \%$ del valor FOB exportado y el $87.14 \%$ de las toneladas exportadas. Dentro de la economía la exportación bananera representa el 2\% del PIB general, 26\% del PIB agrícola, $8 \%$ de las exportaciones generales, $27 \%$ de las exportaciones agropecuarias y $20 \%$ de las exportaciones no petroleras. Las inversiones en el área de producción alcanzan un estimado de 4.000 millones de dólares entre plantaciones cultivadas de banano, infraestructura, empacadoras, puertos, constituyéndose en una de las más importantes por el monto y el alcance que tiene en la economía nacional. De acuerdo a la información que registra el MAGAP, el cultivo de banano representa el 10\% de la superficie total agrícola del Ecuador, teniendo un crecimiento promedio de 3\% desde hace 9 años. En el año 2012 se registraron 7 millones de toneladas métricas de banano producción nacional de este sector, siendo la provincia de los Ríos la principal productora de este producto, seguida de la provincia del Oro y de 
la provincia del Guayas (Análisis del Sector Banano 2013 http://www.proecuador.gob.ec/).

El uso de subproductos agroindustriales en la alimentación o suplementación de bovinos ha originado un proceso que permite dar opción de manejo a los desechos productivos. Este uso de los desechos o remanentes degradables de los productos agroindustriales ha resultado una excelente opción y se han generado muchos estudios para la búsqueda de fuentes de alimentación alternativa. Por este motivo, se han propuesto una serie de proyectos para poder manejar estos desechos, con el fin de optimizar el uso de los recursos y dar pasó a un desarrollo sostenible en la producción bananera. En las empresas clasificadoras y empaquetadoras de banana (fruto de la Musa acuminata Colla, subgrupo Cavendish) de la provincia de los Ríos se obtienen residuos sólidos frescos, compuestos por dos subproductos: las bananas de destrío y el raquis (pedúnculo floral del racimo, donde se insertan las manos de las bananas).

Cuando se cosecha el racimo, solo se está utilizando del 20 al 30\% de su biomasa (Benalcázar et al., 1991), quedando de un 70 a $80 \%$ por utilizar, lo que ha generado una de las principales problemáticas ambientales, puesto que en la mayoría de los casos son incinerados o vertidos a los causes receptores sin tratamiento previo, contribuyendo a la degradación del ecosistema. Sin embargo, algunos productores aprovechan los residuos en la plantación en forma de abono verde y alimentación animal (Vidal et al., 2001). Asimismo, el vástago o raquis, comúnmente se utiliza como alimento para ganado, pero también se ha venido utilizando en forma de harinas (Duque et al., 2000).

Respondiendo a la problemática ambiental detectada, y debido a que los estudios in vivo los alimentos sólo pueden ser evaluados en raciones totales y al hecho de que los mismos requieren considerables recursos y son difíciles de estandarizar, desarrollándose últimamente varias técnicas in vitro. Las técnicas in vitro, descrita por Tilley y Terry (1963), fue modificada por Goering y Van Soest (1970).En base a estas consideraciones se planifico la siguiente investigación con los siguientes objetivos: Evaluar la composición química de fermentación y degradabilidad ruminal in vitro de dietas con diferentes inclusiones de harina banano, y urea; para mejorar las características productivas de los hatos ganaderos de la zona. Determinar los cambios en la degradabilidad de nutrientes (MS) en dietas con diferentes inclusiones de harina de banano y urea. Identificar la variación en el perfil de fermentación ruminal in vitro de dietas con diferentes inclusiones de harina de banano y urea. 


\section{Materiales y Métodos}

El trabajo se realizó en la zona central del trópico húmedo ecuatoriano, la zona de estudio se encuentra ubicada en las coordenadas geográficas $79^{\circ} 15^{\prime}$ hasta los $79^{\circ} 40^{\prime}$ de longitud oeste y $0^{\circ} 40^{\prime}$ hasta $1^{\circ} 20^{\prime}$ de latitud sur, a una altura de 73 a 103 m.s.n.m. El trabajo se desarrolló en el Laboratorio de Rumiología de la Universidad Técnica Estatal de Quevedo, ubicada en el cantón Quevedo, provincia de Los Ríos.

Se aplicó un Diseño Completamente al Azar, con cuatro dietas y cuatro repeticiones; la repetición estuvo conformada o constituida por un frasquito o recipiente para digestibilidad in vitro. Cada frasquito será una unidad experimental que represento a una repetición. Los datos se analizaron utilizando el procedimiento del paquete estadístico DE Eva-A-Dva y las diferencias de medias fueron comparadas usando la Prueba de Tukey $(\mathrm{p}<0,05)$.

Cuadro 1. Dietas con diferentes porcentajes de inclusión de harina de banano y urea

\begin{tabular}{|c|c|c|c|c|c|}
\hline \multirow[t]{2}{*}{ INGREDIENTE } & \multicolumn{4}{|c|}{ PORCENTAJE DE INCLUSION } & \multirow[t]{2}{*}{ TOTAL } \\
\hline & $0 \%$ & $10 \%$ & $20 \%$ & $30 \%$ & \\
\hline MAIZ SECO & 45,3000 & 34,300 & 24,1000 & 14,0500 & 117,7500 \\
\hline POLVILLO DE CONO & 30,0000 & 30,0000 & 30,0000 & 30,0000 & 120,0000 \\
\hline PASTA DE SOYA & 5,0000 & 5,0000 & 5,0000 & 5,0000 & 20,0000 \\
\hline HARINA DE BANANO & 0.0000 & 10,0000 & 20,0000 & 30,0000 & 60,0000 \\
\hline UREA & 0,0000 & 1,0000 & 1,2000 & 1,2500 & 3,4500 \\
\hline RESIDUO DE MAIZ & 15,0000 & 15,0000 & 15,0000 & 15,0000 & 60,0000 \\
\hline PREMIX BROILER & 0.2000 & 0.2000 & 0.2000 & 0.2000 & 0,8000 \\
\hline CARBONATO DE CALCIO & 1,8500 & 1,8500 & 1,8500 & 1,8500 & 7,4000 \\
\hline FOSFATO DICALCICO & 1,15000 & 1,15000 & 1,15000 & 1,15000 & 4,6000 \\
\hline SAL & 1,15000 & 1,15000 & 1,15000 & 1,15000 & 6,0000 \\
\hline TOTAL & 100,00 & 100,00 & 100,00 & 100,00 & 400,00 \\
\hline
\end{tabular}

Determinación de materia seca y/o humedad (para muestras molidas) (A.O.A.C., 1990).Se colocó los crisoles de porcelana en la estufa a $130^{\circ} \mathrm{C}$ por $30 \mathrm{~min}$. Se enfrió por $15 \mathrm{~min}$ en un desecador y se registró el peso. Se pesó $2 \mathrm{~g}$ de muestra molida en cada cápsula, y se colocó en la estufa por 2 h, a $130^{\circ} \mathrm{C}$, seguido, se enfrió en un desecador por 15 min y se registró el peso del crisol más la muestra seca, Los cálculos se realizaron con la siguiente formula:

Humedad $(\%)=\frac{(p i-p f)}{g} x 100 M S(\%)=100-$ humedad $(\%)$

Determinación de cenizas totales y materia orgánica (A.O.A.C., 1990). En un crisol de porcelana se depositó 1 a 2 g de la muestra, seguido se colocó en una mufla con $600^{\circ} \mathrm{C}$ durante 2 horas para carbonizar la muestra. Después se reposó las muestras calcinadas en un desecador de vidrio por 20 minutos, se registró el peso total. 


$$
\begin{gathered}
\text { Cenizas }=\frac{\text { peso de crisol con cenizas }- \text { peso de crisol vacío }}{\text { peso muestra }} \times 100 \\
M O=100-\text { ceniza en base } \sec (\%)
\end{gathered}
$$

Determinación fracciones de fibra FDN, FDA. Se utilizó las técnicas (ANKOM TECNOLOGIA). Se pesó las bolsas (W1), 0.45 a $0.55 \mathrm{~g}$ de muestra (W2), se agregó. acetona y se mantuvo en remojo durante 12 horas. Se colocaron las bolsas en las bandejas del analizador de fibra, se agregó $100 \mathrm{~mL}$ de solución neutro detergente, luego se añadió $40 \mathrm{ml}$ de alfa amilasa, se agitó y se ajustó el temporizador de 75 minutos y cerrado de tapa. Al final de la extracción, se bajó el calor, se abrió la válvula de drenaje lentamente antes de abrir la tapa. Cuando el proceso de lavado se completó, se colocó las bolsas en un vaso de precipitación de $250 \mathrm{~mL}$ y se añadió acetona durante 3 a 5 min, se secó al aire y luego en la estufa a $102^{\circ} \mathrm{C}$ hasta que la acetona se ha evaporado completamente, se puso las bolsas en un desecador, se dejó enfriar a temperatura ambiente y se pesó las bolsas (W3).

\section{Digestibilidad “in vitro” de la Materia Seca (MS) a partir de las técnicas propuestas por Tilley y Terry (1963)}

Para el desarrollo de la primera fase de esta técnica se procedió al pesado de $0.7 \mathrm{~g}$ de la muestra, se adicionó $40 \mathrm{~mL}$ de saliva artificial y 10 $\mathrm{mL}$ de licor ruminal, se incubó 48 horas a 39 grados ${ }^{\circ} \mathrm{C}$ a baño de maría con agitación, también se adicionó $6 \mathrm{~mL}$ de $\mathrm{HCl}$, luego $2 \mathrm{~mL}$ de solución pepsina al 5\%, se filtró el contenido en crisol secado y tapado previamente, se secó en estufa a 105 grados ${ }^{\circ} \mathrm{C}$ por 12 horas dando por finalizada la DIVMS, se realizaron los siguientes cálculos.

$$
D M S=\frac{\text { muestra }(g)-\text { residuo }(g)}{\text { muestra }(g)} \times 100
$$

\section{Segunda fase}

Se extrajo con una bomba de vacío el líquido ruminal de 2 bovinos Brahman fistulados de $500 \pm 25 \mathrm{~kg}$ de peso vivo, que fueron alimentados con dieta base de pasto picado suplementado con banano de rechazo, este líquido de ambos animales se mezcló y se filtró con 6 capas de gasa, depositándose en un termo precalentado a $39{ }^{\circ} \mathrm{C}$ y gaseado con $\mathrm{CO}_{2}$. Una técnica similar fue empleado por (Giraldo et al. (2006) en la comparación de dos técnicas in vitro e in situ para estimar la digestibilidad verdadera en varios forrajes tropicales. El medio (40 mL de saliva, McDougal y $10 \mathrm{~mL}$ de líquido ruminal) se depositó en frascos de $100 \mathrm{~mL}$, se insertaron las bolsitas F57 ANKOM previamente pesadas las bolsas vacías más las dietas en estudio. La saliva de Mc Dougal incluye un tampón o buffer que puede tener efecto en los datos de $\mathrm{pH}$. 
Los frascos fueron gaseados con $\mathrm{CO}_{2}$, tapados para mezclar su contenido y colocados en Baño María a $39{ }^{\circ} \mathrm{C}$. La incubación se realizó durante $0,2,6,14,24,48,72$ horas.

En los respectivos tiempos se fueron sacando los frascos en grupo de dieciséis de los baños maría y se realizó la medición del $\mathrm{pH}$.

Se utilizó el siguiente modelo estadístico:

Yij $=\mathrm{u}+\mathrm{ti}+$ Eij Donde: $\mathrm{Yij}=$ variable de respuesta

$\mathrm{u}=$ media general

ti $=$ Efecto del tratamiento

Eij $=$ Efecto del error experimental

\section{Resultados y Discusión}

Composición química de la dieta con inclusión de harina de banano y urea en distintos (\%).

Materia Seca, Cenizas, Materia orgánica, FDN, FDA (\%)

En cuanto al contenido de MS, FDN, y FDA se reporta que estadísticamente $(\mathrm{P}>0.05)$ no existen diferencias entre los tratamientos (Cuadro 2). En cuanto al porcentaje de cenizas, el T3 con inclusión de 30\% de harina de banano y $1.25 \%$ de urea, es superior a los demás tratamientos; mientras, los porcentajes de MO fueron altamente significativos, incrementándose su cantidad en los tratamientos T0 y T1. Los valores de FDN y FDA tuvieron igual comportamiento en todos los tratamientos.

Cuadro 2. Composición química de Materia seca, Cenizas, Materia orgánica, FDN, FDA.

\begin{tabular}{|c|c|c|c|c|c|c|}
\hline Variable & T0 & $\mathrm{T} 1(10 \%)$ & T2 (20\%) & ГЗ (30\%) & SEM & ROB.0.05 \\
\hline $\mathrm{N}^{\circ}$ de observaciones & 4 & 4 & 4 & 4 & & \\
\hline Materia seca & $89.4 \mathrm{a}$ & $89.5 \mathrm{a}$ & $89.4 \mathrm{a}$ & $89.7 \mathrm{a}$ & 0.03 & 0.2008 \\
\hline Cenizas & $9.83 \mathrm{~b}$ & $9.54 \mathrm{~b}$ & $10.95 \mathrm{ab}$ & $11.68 \mathrm{a}$ & 0.19 & $<0.0001$ \\
\hline Materia orgánica & 90.17 а & 90.46 а & 89.05 b & $88.32 \mathrm{~b}$ & 0.11 & $<0.0001$ \\
\hline $\begin{array}{l}\text { FDN } \\
0.0020\end{array}$ & \multicolumn{2}{|c|}{63.27 a } & $64.41 \mathrm{a}$ & 65.08 a & 66.51 & a $\quad 0.03$ \\
\hline $\begin{array}{l}\text { FDA } \\
0.0511\end{array}$ & \multicolumn{2}{|c|}{59.8 a } & $60.0 \mathrm{a}$ & $61.5 \mathrm{a}$ & 62.0 & 0.03 \\
\hline
\end{tabular}

Promedios con letras iguales entre columnas no difieren significativamente de acuerdo a la prueba de Tukey $(\mathrm{P}<0.05)$ 


\section{Degradabilidad in vitro de dieta con inclusión de harina banano y urea en distintos (\%).
Degradabilidad de la MS (\%) a 0, 2, 6, 14, 24, 36, 48, 72 horas de incubación

A medida que transcurre el paso de las horas de 0 a 72 horas en todos los tratamientos hay aumento de la degradabilidad de MS, fue significativo el T1 a las 24 y 36 horas de incubación (Cuadro 3).

La intensidad de este proceso degradativo es variable y depende de la magnitud de la fracción potencialmente degradable y de su tiempo de retención en el rumen. La digestión en el rumen de las fracciones potencialmente degradables del almidón y la proteína puede ser descrita por un modelo cinético de desaparición de este compartimento (Ørskov y McDonald, 1979), Ello puede tener una importante incidencia en la eficiencia de utilización de la dieta y en la respuesta productiva del animal, dada la influencia que el lugar de digestión tiene sobre el tipo de nutrientes absorbidos (Thomas y Rook, 1981).

En investigaciones in situ la degradación potencial ruminal del banano verde alcanzo 90.9 \%. Pérez, et al 1989.

Cuadro 3. Degradabilidad de la materia seca (\%) en distintas horas de incubación

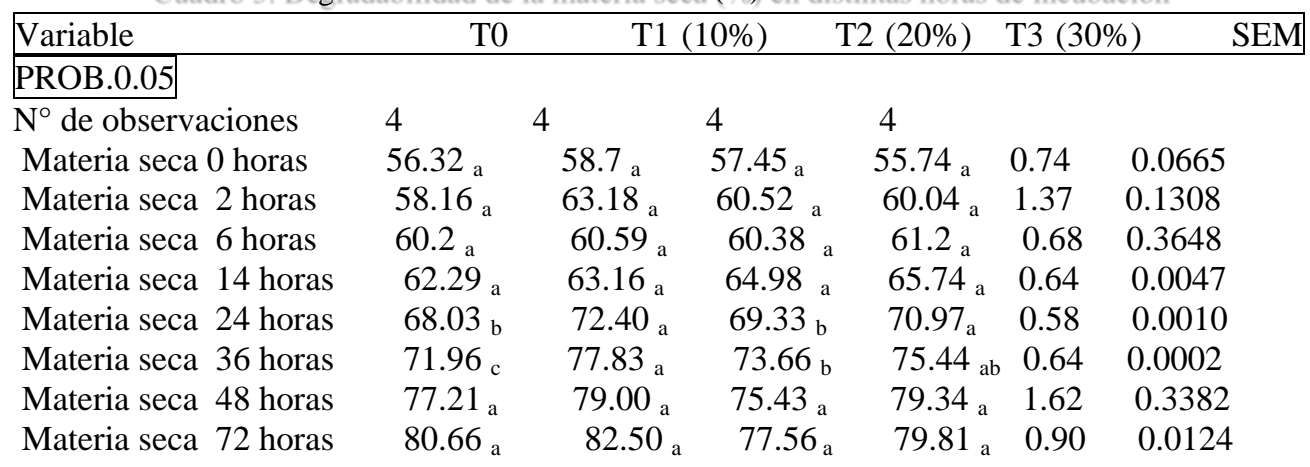

Promedios con letras iguales entre columnas no difieren significativamente de acuerdo a la prueba de Tukey $(\mathrm{P}<0.05)$

\section{Fermentación ruminal}

\section{pH ruminal a $0,2,6,14,24,36,48,72$ horas de incubación}

$\mathrm{El} \mathrm{pH}$ ruminal de la dieta obtenido en transcurso de las distintas horas de incubación, indican que a las 0 y 6 horas se registra promedios de $\mathrm{pH}$ de 8.16 y 6 y a las 72 horas un pH 7.15 El Shazly et al. (1961) manifiesta que la celulolisis podría recuperarse parcialmente incorporando urea y otros nutrientes por encima de las necesidades. En otras investigaciones donde utilizaron cascara de banano maduro hubo estabilidad del $\mathrm{pH}$ ruminal debido a que tiene la capacidad de producir saliva inducida por la forma en que es ofrecido el material y por la capacidad buffer de la CBM. no solo por la 
capacidad de la pared celular de absorber iones de $\mathrm{H}+$, como función de los grupos carboxilo presente en los carbohidratos estructurales (Williams et al., 1987). Los protozoos también tienen una función importante en la degradación del almidón, engullen los gránulos, los fermentan intracelularmente y almacenan el exceso de energía como amilopectina, evitando así su rápida degradación por parte de las bacterias y un descenso pronunciado del pH ruminal ( Mackie et al., 1978).

La saliva contiene bicarbonato (HCO3) y fosfato (HPO4) que le dan un $\mathrm{pH}$ alcalino a la saliva (8.2 a 8.4) y que el rumen actúa como tampón frente a la producción de ácidos (Van Lier y Regueiro, 2008). El tratamiento con formaldehido o amoniaco reduce la adhesión bacteriana y por tanto, la velocidad de degradación (Cheng et al., 1991).

Es así como Kaufmann (1976) nos señala que la composición de la dieta y las prácticas de alimentación influyen sobre el $\mathrm{pH}$ ruminal, ya que, a medida que se incrementa la proporción de ingredientes de fermentación rápida, disminuye el $\mathrm{pH}$ y viceversa. Aun cuando no puede definirse un $\mathrm{pH}$ óptimo en el medio ruminal, los microorganismos presentan cierto intervalo en el cual se reproducen mejor y su metabolismo es más eficiente. Los protozoarios manifiestan su principal desarrollo a un $\mathrm{pH}$ cercano a 6.5 y son severamente afectados en $\mathrm{pH}$ superiores a 8 e inferiores a 5.5, siendo este último uno de los factores que más afectan su población (Hungate 1966; Hino et al., 1973).

Williams et al. (1983) y Cheng et al. (1984) concluyeron que en condiciones ruminales de $\mathrm{pH}$ bajo, el ataque bacteriano a las paredes celulares es difícil y por lo tanto se reduce su digestión. Se considera que un pH ruminal superior a 6.2 es el óptimo para obtener una buena digestión de celulosa (Rodríguez y Llamas, 1990). La importancia de la amortiguación del pH a nivel ruminal tiene la finalidad de mantener el metabolismo de los microorganismos ruminales en un rango óptimo para su crecimiento.

La disminución en el $\mathrm{pH}$ del rumen reduce la viabilidad de las bacterias celulolíticas y por tanto, se reduce la actividad sobre los carbohidratos estructurales (Williams et al., 1983).

El descenso del $\mathrm{pH}$, frecuentemente observado en dietas concentradas, ha sido considerado el principal factor responsable de la disminución de la degradación de la fibra observada en dietas numerosos estudios in vitro, e in situ, han observado una disminución en la celulolisis cuando el $\mathrm{pH}$ desciende por debajo de seis y se ha considerado el umbral crítico para la celulolisis (Mould et al., 1983; Houver, 1986; Shriver $t$ al., 1986; Russell y Wilson, 1996).

El-Shazly et al. (1961) notaron que la materia seca (MS), la digestibilidad de forrajes se reduce en presencia de almidón o alimentos ricos en almidón, principalmente debido a la competencia por los nutrientes 
esenciales por microorganismos amilolíticas y celulolíticas en el rumen, lo que resulta en la proliferación de las bacterias para digerir almidón. Fermentación rápida de almidón conduce a una disminución en el $\mathrm{pH}$ del rumen que anima a los microorganismos amilolíticas a proliferar y competir con éxito contra las bacterias celulolíticas, que crecen en un pH más alto (del molde y Orskov, 1983; Molde et al., 1983).

\section{Conclusion}

Se pudo comprobar que se pueden aprovechar residuos de la cosecha y pos cosecha del banano como el pseudotallo y raquis para la alimentación animal, troceadas o en harinas y, sustituir otras harinas tradicionales en especial harinas de subproductos de cereales como el trigo, arroz y el maíz en la alimentación animal por su rico contenido en fibra.

La degradabilidad de la materia seca (MS) de la dieta obtenida, confirman la desaparición de nutrientes a medida que pasa el tiempo, manteniendo un nivel de desaparición similar a otros alimentos estudiados en otras investigaciones, alcanzando valores superiores al $70 \%$ de digestibilidad, lo cual garantiza la calidad de la dieta.

El $\mathrm{pH}$ en la fermentación ruminal in vitro en dieta con inclusiones de harina de banano y urea de 0 a 6 y de 6 a 72 horas no descendió a niveles de umbrales críticos peligroso para la celulolisis.

\section{References:}

Bananas and Food Security International Symposium. (1998, Cameroon). 1998. Les production bananieres: un enjeu économique majeur por la sécurité alimentaire. France, International Network for the Improvement of Banana and Plantain. 797 p.

Cheng KJ,.CW Forsberg H. minato, y J W Costerton.1991 Microbial ecology and physiology of fed degradation within the rumen. Pág 595-623 en: Physiological aspects of digestion and metabolism in runinants. T Tsuda , T SasaKi, y R Kawashima, Eds. Academic Press. London.

Cheng, K.J., Stewart, C.S., Dinsdale D., Costerton, J.W. 1984 Electron microscopy of the bacteria involved in the digestion of plant cell walls. Anim. Feed Sci. Technol. 10:93.

Duque A., Bohórquez Y., (2000). Modelo para la determinación de pérdidas postcosecha del plátano Dominico-Hartón (Musa ABB SIMMONDS) Producido en el Departamento del Quindío. Poscosecha y Agroindustria del plátano en el eje cafetero de Colombia. Corpoica, Universidad del Quindío, ASIPLAT, Comité Departamental de cafeteros del Quindío, COLCIENCIAS, Fudesco, Armenia, pp. 153-158.

El-Shazly K, Dehorty BA, Johnson RR (1961) Efecto del almidón en la digestión de la celulosa in vitro y in vivo por los microorganismos del 
rumen. J. Anim. Ciencia. 20 : 268-273. [ Links Hungate, R. E1966. The Rumen and its Microbes. Academic Press, N.Y.

Hino, T., KametakaAnd M. Kandatsu, M.1973 The cultivation of rumen oligotrich protozoa. I. Factors influencing the life of Entodinia. J. Gen. Microbiol. 19:305.

Hoover, WA.1986. Chemical factors involved in ruminal fiber digestion. J, Dairy Sciba: 2755-2766.

Giraldo L, et al. 2007. Comparación de dos técnicas in vitro e in situ para estimar la digestibilidad verdadera en varios forrajes tropicales. Revista Colombiana de Ciencias Pecuarias. 20 (2007): 269-279.

Kaufmann, W. 1976 Influence of the composition of the ration and the feeding requency on pH-regulation in the rumen and feed in take in ruminants. Livest. Prod. Sci. 3:103-114.

Molde FL, Orskov RE (1983) La manipulación del pH del líquido ruminal y su influencia en celulolisis en sacco degradación de la materia seca y la microflora del rumen de ovejas prestados tanto heno o concentrado. Anim. Alimente Ciencia. Technol. 10 : 1-14.

Mould, F.L..., ER Orskov, SO Mann 1483/84a.Associative effects admixed feets. I, Effects of type and level supplementation and the influence of the rumenfluid ph oncellulolysis in vivo and matter digestion of various roughages. Anim. Feed Sci.Technol. 10:15-30

Mackie, R, I., F. M. C. Gilchrist, A. M. Robberts, P.E. Hannah, y H. M. Schwartz. 1978. Microbiological and changes in the rumen during the stepwise adaption of sheep to high concentrate diets. J. Agric. Sci. Camb. 90: 241-250.

Ørskov, E.R. y McDonald,I. (1979) The estimation of protein degradability in the rumen from incubation measurements weighted according to rate of passage.J. Agric. Sci., Camb. 92, 499.

Pérez, E. Ruiz, M. Pezo D (1989) Suplementación de bovinos con banano verde Efecto sobre la degradación ruminal del banano.

Russell,B y D.B. Wilson 1996. Why are ruminal cellulolytic bacteria unable to digest cellulose at low ph? JDairy Sci. 79: 1503-1509

Rodríguez, G.F., Llamas, L.G. 1990 Digestibilidad, balance de nutrimentos y patrones de fermentación ruminal. In: R.A. Castellanos, L.G. Llamas y S. A. Shima, Eds. Manual de técnicas de investigación en ruminología. Sistemas de Educación Continua en Producción Animal en México, A.C. México, D.F. pp. 95-126.

Shriver, B.J., W.H. Hoover ,J.P. Sargent, R3. Crawford, Jr., y W.V Thayne. 1986 Fermentation of a high concentrate diet as affected by ruminal ph and digesta flow. J Dairy Sci 83:313-321Tilley J M and Terry R A 1963 A two stage technique for the in vitro digestion of forage crops. Journal of British Grassland Society. 18: 104-111 
Thomas, P.C. y Rook, J.A.F. (1981) En: Recent developments in Ruminant Nutrition. W. Haresign y D.J.A. Cole (eds). Butterworths, London. pp: 157. Vidal F.I., Pereira E., Sotolongo R., Quintana Y., Ortiz, A., García A., Ly, J. (2001). Efecto de la suplementación con seudotallo de plátano sobre la salud y el peso al sacrificio de cerdos comerciales. Revista Producción Animal, Vol 13 No. 1, Universidad de Camagüey, pp.67-69.

Van Lier, E., Regueiro M. 2008 Digestión en reticulo Rumen Curso de Anatomía y Fisiología Animal Montevideo Uruguay, 15: 1-28

Williams, P.E.V., Macdearmid, A., Innes, G.M., Brewer, A. 1983 Turnips with chemically treated straw for beef production. 2. Effect of turnips on the degradability of straw in the rumen. Anim. Prod. 37:189.

Williams ,PE.V;Fallon, R.,J; Innes, G. m; Garth Waite, P. 1987. Effects on food intake, rumen de Velopment and live weight of calves of replacing barley with sugar beet citrus pulp in starter diet. Animal Production 44:6573.

\section{References bibliográficas (internet)}

www.proecuador.gob.ec

www.banaexport.com.

library.Thinkquest.org , 